\title{
ÇCKNT Katkılı ve Katkısız CETP Kompozit Malzemelerin TiN Kaplamalı Zımba İle Delinmesinde Kesme Kuvveti Değişiminin İncelenmesi
}

\author{
$*^{1}$ Ferhat Ceritbinmez \\ ${ }^{* 1}$ Haier Europe - Candy Hoover Group, Eskişehir, Türkiye
}

\begin{abstract}
Özet :
Endüstride başta otomotiv ve beyaz eşya sektörlerinde yaygın olarak kullanılan özdeş ve imalat sayısı yüksek olan metal, plastik ve kompozit malzemelerin delinmesinde saç metal kalıpları tercih edilmektedir. Gelişen teknoloji, artan üretim kapasitesi ve rekabet koşulları imalatçıları daha az maliyetle daha fazla üretim yapmaya ve üretim proseslerini iyileştirmeye teşvik etmektedir. $\mathrm{Bu}$ çalışmada ÇCKNT katkılı ve katkısız CETP kompozit malzemelere $0.025 \mathrm{~mm}, 0.10 \mathrm{~mm}, 0.15 \mathrm{~mm}$ kesme boşluğu bulunan kalıplarda kaplamasız ve TiN kaplamalı zımbalar ile delik delinerek kesme kuvveti değişimi incelenmiştir. Yapılan çalışma neticesinde TiN kaplamalı zımba kullanılarak yapılan delme işlemlerinde ihtiyaç duyulan ortalama kesme kuvveti'nin kaplamasız SBZ zımba kullanımına göre katkılı ve saf kompozitlerde sırası ile \% 10.10 ve \% 4.50 oranında azaldığı tespit edilmiştir. Ayrıca kalıp üzerinde bulunan kesme boşluğunun azalması ile kesme kuvveti ihtiyacının arttığı ölçülmüştür.
\end{abstract}

Anahtar kelimeler : CETP, ÇCKNT, TiN, Kesme Kuvveti

\section{Investigation of Cutting Force Variation in Punching by TIN Coated Punch of GFRP Composite Materials With and Without MWCNTs}

\begin{abstract}
:
Sheet metal molds are preferred for punching identical metal, plastic and composite materials, which are widely used in the automotive and household appliances sectors in the industry. Developing technology, increasing production capacity and competition conditions encourage manufacturers to produce more with less cost and to improve production processes. In this study, the variation in cutting force was investigated by drilling holes with uncoated and TIN coated punches in molds with a cutting clearance of $0.025 \mathrm{~mm}, 0.10 \mathrm{~mm}, 0.15 \mathrm{~mm}$ on pure and MWCNTs-reinforced GFRP composite materials. As a result of the study, it was determined that the average cutting force needed in punching processes using TIN coated punches decreased by $\% 10.10$ and $\% 4.50$ respectively in doped and pure composites compared to uncoated SBZ punch use. In addition, it was measured that with the reduction of the cutting clearance on the die, the need for cutting force increased.
\end{abstract}

Key words: GFRP, MWCNTs, TIN, Cutting Force

*Corresponding author: Address: Haier Europe - Candy Hoover Group, Organize Sanayi Bölgesi 8.Cd. No:1 26110, Eskişehir, TURKEY. E-mail address: ferhatceritbinmez@gmail.com, Phone: +90222360650 


\section{Giriş}

Cam elyaf takviyeli polimer (CETP) kompozitler sahip oldukları yüksek özgül mukavemet, uygun korozyon ve yorulma direnci özelliklerinden dolayı günümüzde birçok kullanım alanına sahip malzemeler haline gelmiştir [1-4]. Bu malzemeler grafen, bor nitrür, çok cidarlı karbon nanotüp (ÇCKNT) gibi katk1 malzemeleri kullanılarak katkılandırılmakta ve sahip oldukları özellikler geliştirilmektedir [5-7]. Çeşitli uygulama alanına sahip bu malzemelerin kullanım yerlerine monte edilebilmesi için delik ihtiyacı doğmaktadır [8-9]. Bu ihtiyaç lazer kesim, su jeti kesim, orbital ve konvensiyonel delme, zımba ve kalıp ile delme yöntemleri kullanılarak karşılanmaktadır [10]. Her bir yöntemin avantaj ve dezavantajları bulunmaktadır. Zımba ve kalıp kullanılarak delik elde etme yönteminin seri üretime uygun özdeş parça üretimi gibi bir çok avantajı mevcuttur. Bu yöntemde kullanılan malzemeler ve çalışma parametreleri iyileştirilerek daha verimli sonuçlar elde edilebilir. Araştırmacılar farklı malzemelere zımba ve kalıp kullanarak delik delebilmek için zımba kesme formu, kaplama cinsi ve kesme boşluğu gibi parametreler üzerine çalışmalar yapmaktadır. Qiao ve arkadaşları, Zr36.6Ti31.4Nb7Cu5.9Be19.1 metalik cam matriks kompozitleri işlemek için bir krank presi ve kalıp kesme makinesinden bir dinamik kesme delme yöntemini kullanmışlar. Malzemelerin kesilmesi esnasında gevrek bir kırılma hakim iken, zımba ile delme işlemi sonucunda kesilen malzemede buruşma veya makroskobik çatlak görülmemiştir [11]. Chan ve arkadaşları, çift kademeli zımbalar kullanarak kompozit malzemelere delikler açmış, elde edilen deliklerin alt ve üst yüzeylerinin daireselliğini ve kesim kalitesini incelemişlerdir. Kesme boşluğunun azalmasıyla veya zımba çapının artmasıyla basma gerilmesi ve sıkışma yükünün arttığını; kademeli zımba kullanımının, kesme boşluğunun maksimum sıkıştırma yükü üzerindeki etkisini azalttığını rapor etmişlerdir [12]. Zain ve arkadaşları, kompozit malzemelerin matkap kullanılarak delinmesine alternatif olarak zımba kullanılarak delinmesini araştırmış ve \%1 kesme boşluklu kalıpta farklı zımba profillerinin delik kalitesine etkisini analiz etmişlerdir. Kesilen deliklerde ölçüsel hassasiyet, çapaklanma, delaminasyon ve eksik kesme gibi kusurlar incelenmiştir. Zımba kesme ağızları $20^{\circ}, 30^{\circ}$ ve $12,5^{\circ}$ bilenmiş ayrıca konik, kap şeklinde ve tek yönlü bilenmiş 6 farklı zımba profili ile deneyler yapmışlar. Konik şekilli zımba modeli kullanılarak en iyi sonuçların elde edildiğini rapor etmişlerdir [13]. Abdullah ve arkadaşları, kompozit paneller üzerinde delik elde etmek için matkap ile delme ve freze çakısı ile orbital delme gibi geleneksel yöntemlerin yerine zımba ile delme gibi alternatif bir yöntemi kullanmışlardır. Farklı profilli zımbalar kullanılarak delinen kompozit malzemelerin delik etrafındaki delaminasyon hasarını ölçmek için odak değişimi tekniğine dayalı Alicona makinasını kullanmışlardır. Delaminasyonun, kompozit panelin yapısal bütünlüğünü etkileyebilecek yapısal bir hasar ölçüsü olduğunu vurgulamışlardır [14]. Bu çalışmada literatürden farklı olarak nanopartikül katkılı ve katkısız malzemelere üç farklı kesme boşluğu bulunan kalıpta kaplamasız ve Tin kaplı zımbalar kullanılarak delikler delinmiş, delik delme sürecinde kesme kuvveti değişimi incelenmiştir.

\section{Materyal ve yöntem}

\subsection{CETP ve \% 0.1 ÇCKNT katkılı kompozit test malzemeleri}

Bu çalışmada ÇCKNT katkılı ve katkısız CETP malzemeler zımba ve kalıp kullanılarak delik delmek için seçilmiştir. Seçilen malzemelerin mekanik özellikleri Tablo 1'de verilmiştir. Her iki 
malzeme 8 tabaka cam elyafının epoksi reçine ile vakum infüzyon yönteminde lamine edilmesi ile üretilmiştir. ÇCKNT katkılı CETP malzeme üretiminde nano partikül katkı oran \% 0.1 gr olarak tanımlanmıştır, üretim sonrası katkılı kompozit malzemesinin rengi nanopartikül rengi olan siyah olmuştur. CETP ve ÇCKNT katkılı kompozit test numune kalınlıkları sırası ile $1.70 \pm 0.1 \mathrm{~mm}$ ve $1.50 \pm 0.1 \mathrm{~mm}$ olarak ölçülmüştür. Tabaka olarak üretilmiş levhalar dekupaj testere yardımı ile 20 × 20 mm ebatlarında kesilerek test numunesi olarak kullanılmıştır.

Tablo 1. Katk1lı ve katkısız kompozit malzemelerin mekanik özellikleri

\begin{tabular}{|c|c|c|c|c|c|c|}
\hline $\begin{array}{c}\text { Malzeme } \\
\text { (\% 0.1 ÇCKNT) }\end{array}$ & $\begin{array}{c}\text { Yoğunluk } \\
\left(\mathrm{g} / \mathrm{cm}^{3}\right)\end{array}$ & $\begin{array}{c}\text { Elastisite } \\
\text { Modülü } \\
\text { (GPa) }\end{array}$ & $\begin{array}{l}\text { Maksimum } \\
\text { Kuvvet } \\
(\mathbf{k N})\end{array}$ & $\begin{array}{c}\text { Maks.Çekme } \\
\text { Gerilmesi } \\
\text { (Мpa) }\end{array}$ & $\begin{array}{c}\text { Kopma } \\
\text { Uzama } \\
(\%)\end{array}$ & $\begin{array}{c}\text { Parça } \\
\text { Kalınlığı } \\
(\mathbf{m m})\end{array}$ \\
\hline Katkısız Kompozit & 1.62 & 22.97 & 13.74 & 338.811 & 2.16 & $1.70 \pm 0.1$ \\
\hline Katk1l1 Kompozit & 1.59 & 24.99 & 14.53 & 364.303 & 1.29 & $1.50 \pm 0.1$ \\
\hline
\end{tabular}

\subsection{Zimba ve kalıp malzemeleri}

Kompozit test numunelerini delmek için $8 \mathrm{~mm}$ çapında 1.3343 malzemeden yapılmış 62-64 HRC sertliğe sahip kaplamasız SBZ (silindirik başlı zımba) ve tamamen titanyum nitrür (TiN) kaplamalı silindirik başıı zımbalar kullanılmıştır (Şekil.1). Zımbaların komple kaplanmasında dış katmanların 1sı ve sürtünmeye karşı direnç sağlaması, kayganlığının arttırılması amaçlanmıştır bu sebeple parlak yüzey ve en az sürtünme kuvveti için yüzeyler polisaj yaptırılmıştır.

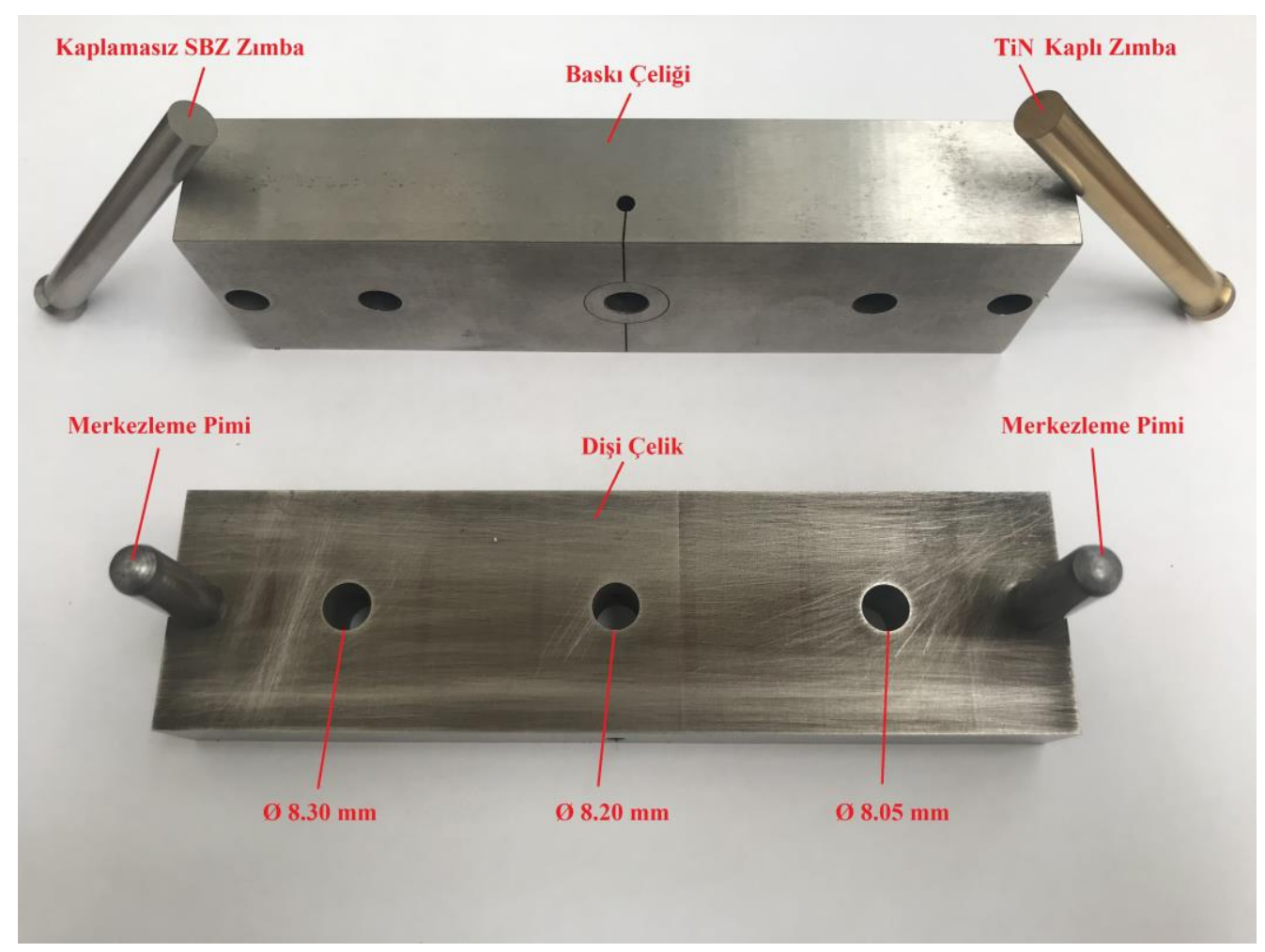

Şekil 1. Delme kalıbı ve zımbaları 
Kalıp malzemeleri 60-62 HRC sertliğe sahip 1.2379 çelik malzemeden yapılmıştır. Dişi çelik üzerine önce hızlı delik delme (EDM - Electrical discharge machining) tezgahında pilot delik açılmış daha sonra tel erozyon tezgahında (WEDM - Wire Electrical discharge machining) hassas şekilde $\varnothing 8.05 \mathrm{~mm}, \varnothing 8.20 \mathrm{~mm}, \varnothing 8.30 \mathrm{~mm}$ çapında delikler açılmıştır. Bu şekilde $0.025 \mathrm{~mm}$, $0.100 \mathrm{~mm}, 0.150 \mathrm{~mm}$ kesme boşluğu uygulanarak kesme kalıbı (aparatı) hazırlanmıştır. Baskı çeliğinden (tutucu plaka) boşluklu geçen zımba malzemesinin dişi çelikte bulunan delikleri merkezleyebilmesi için dişi çelik üzerine yerleştirilen sabit merkezleme pimleri kullanılmıştır.

\subsection{Basma test cihazı}

Kalıp ve zımba kullanılarak delik delmek için ihtiyaç duyulan kuvvet WDW-20 (20 kN) bilgisayarlı elektronik üniversal çekme ve basma test cihazı kullanılarak sağlanmıştır. Basma aparatlarının zımba kafasına $100 \mathrm{~mm} /$ dak hızla bastırılması neticesinde dişi ve baskı çeliği arasına konulan malzemeler delinmiştir. Kesme sırasında oluşan kuvvetler WDM test kontrol yazılımı üzerinden okunmuştur. Her bir kesme boşluğu için yapılan testlerde zımba ve kalıp baskı tablasının altına dik olarak pozisyonlanarak delme işlemleri tamamlanmıştır.

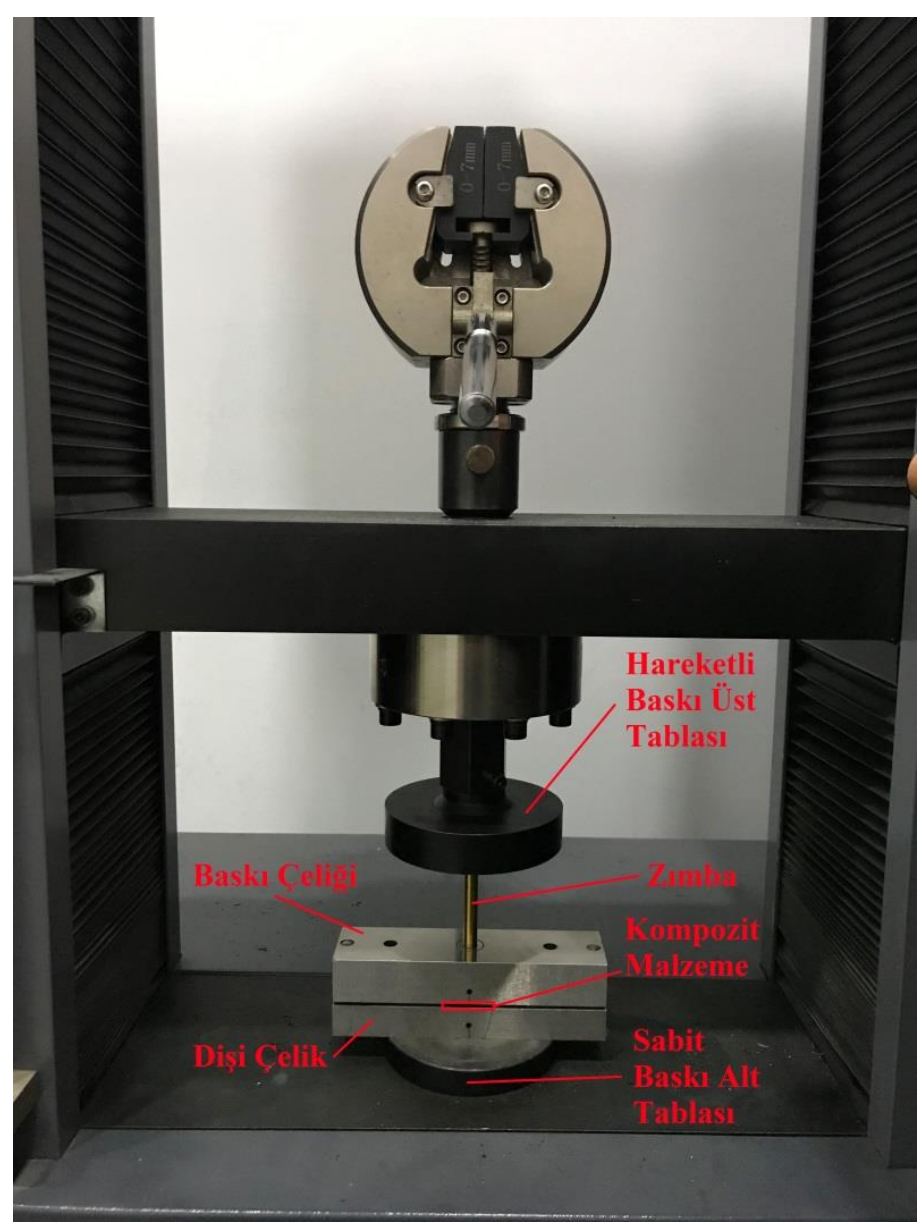

(a)
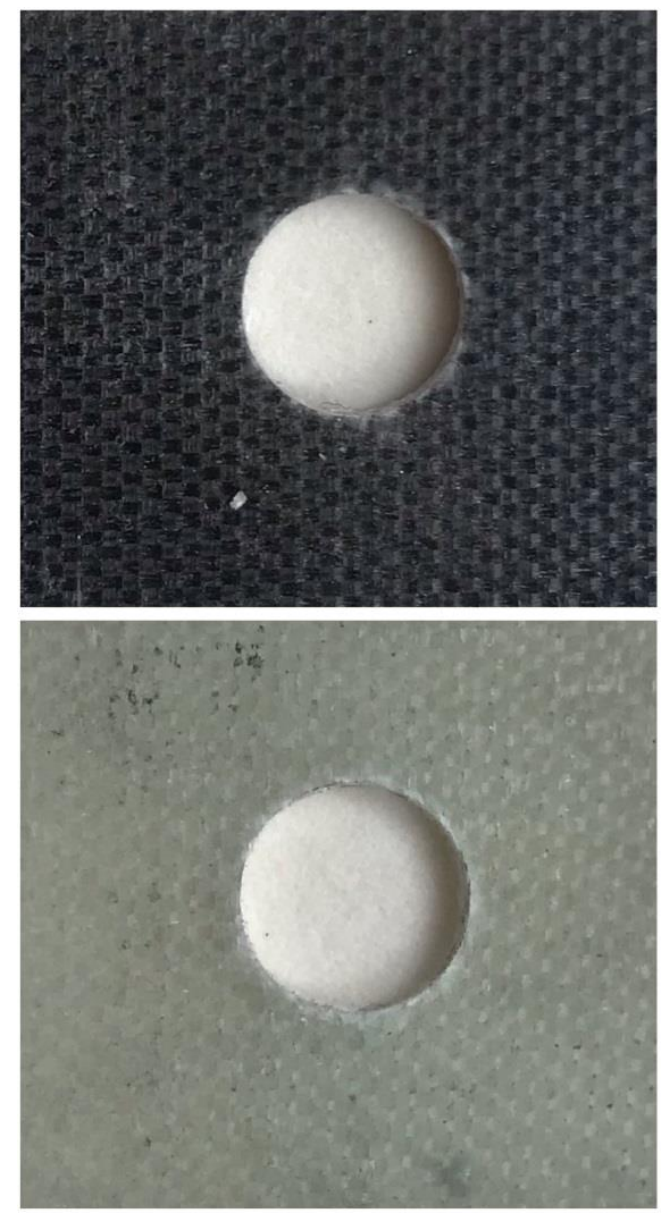

(b)

Şekil 2. Test düzeneği : (a) Basma test cihazı, (b) Katkılı ve katkısız test numunesi 


\section{Deneysel sonuçlar ve tartışma}

Bu çalışmada 20 x 20 mm ebatlarında hazırlanan ÇCKNT katkılı ve katkısız kompozit plakaların tam orta noktalarına TiN kaplamalı ve kaplamasız zımbalar kullanılarak delik delinmiştir. Deliklerin delinmesinde $0.025,0.100,0.150$ kesme boşluğu olan basit kalıp kullanılarak kesme işleminde gerekli olan kesme kuvveti tespit edilmiştir. Elde edilen sonuçlar Tablo 2'de gösterilmiştir.

Tablo 2. Test parametreleri ve sonuçları

\begin{tabular}{ccccccc}
\hline $\begin{array}{c}\text { Test } \\
\text { No }\end{array}$ & $\begin{array}{c}\text { Test } \\
\text { Malzemesi }\end{array}$ & $\begin{array}{c}\text { Zımba } \\
\text { Tipi }\end{array}$ & $\begin{array}{c}\text { Kesme } \\
\text { Hizi } \\
(\mathbf{m m} / \mathbf{d a k})\end{array}$ & $\begin{array}{c}\text { Kesme } \\
\text { Boşluğu } \\
(\mathbf{m m})\end{array}$ & $\begin{array}{c}\text { Kesme } \\
\text { Kuvveti } \\
(\mathbf{N})\end{array}$ & $\begin{array}{c}\text { Ortalama } \\
\text { Kesme Kuvveti } \\
(\mathbf{N})\end{array}$ \\
\hline 1 & & & 100 & 0.025 & 4272.500 & \\
2 & ÇCKNT Katk111 & SBZ & 100 & 0.100 & 3870.680 & 3981.767 \\
3 & & & 100 & 0.150 & 3802.120 & \\
4 & & & 100 & 0.025 & 3913.720 & \\
5 & ÇCKNT Katk111 & TiN & 100 & 0.100 & 3676.710 & 3579.263 \\
6 & & & 100 & 0.150 & 3147.360 & \\
7 & & & 100 & 0.025 & 5090.490 & \\
8 & Katk1sız & SBZ & 100 & 0.100 & 4164.180 & 4715.037 \\
9 & & & 100 & 0.150 & 4890.440 & \\
10 & & & 100 & 0.025 & 4941.830 & \\
11 & Katk1sız & TiN & 100 & 0.100 & 4348.250 & 4501.547 \\
12 & & & 100 & 0.150 & 4214.560 & \\
\hline
\end{tabular}

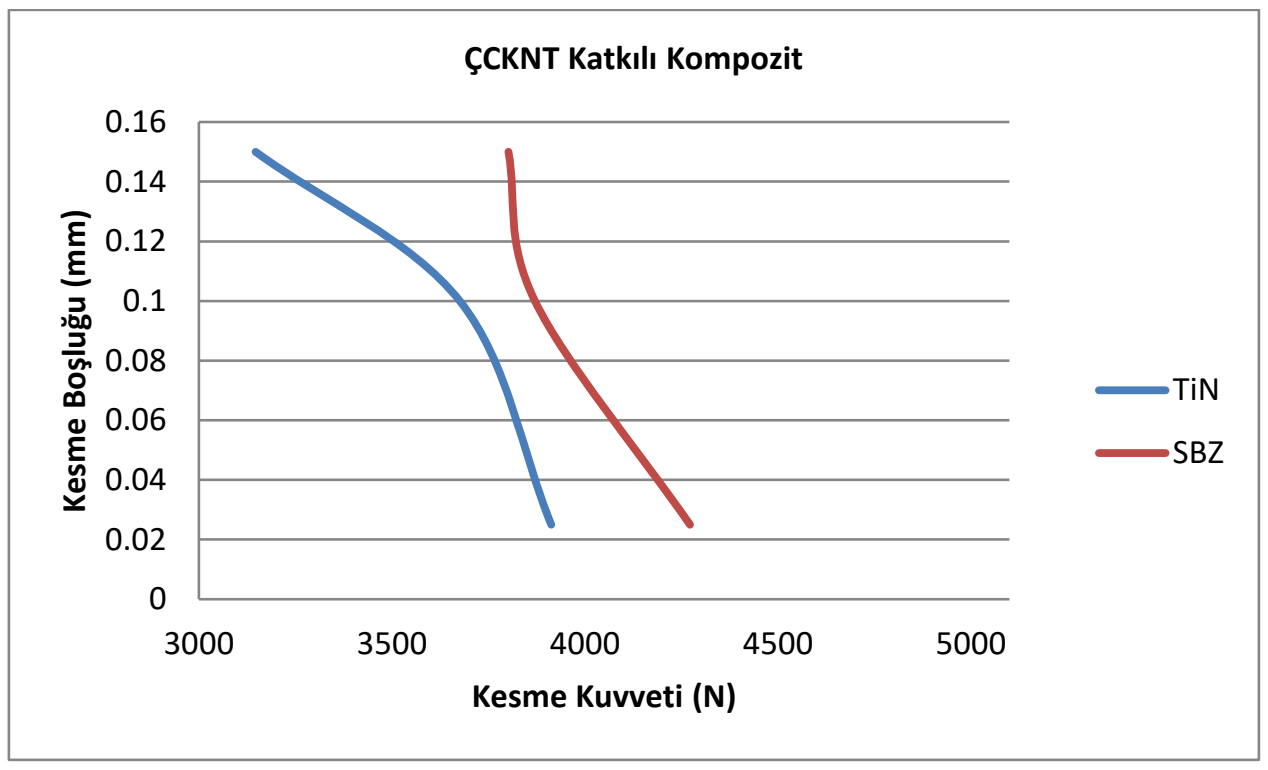

Şekil 3. ÇCKNT katkılı kompozit kesimde kesme kuvveti değişimi 
Genel olarak Şekil 3 ve Şekil 4'te görüldüğü gibi kalıp içerisinde kesme boşluğunun azalmasıyla artan sürtünme ve malzeme yığılması (malzemenin sıkışması) kesme kuvvetinin artmasına sebep olmuştur.

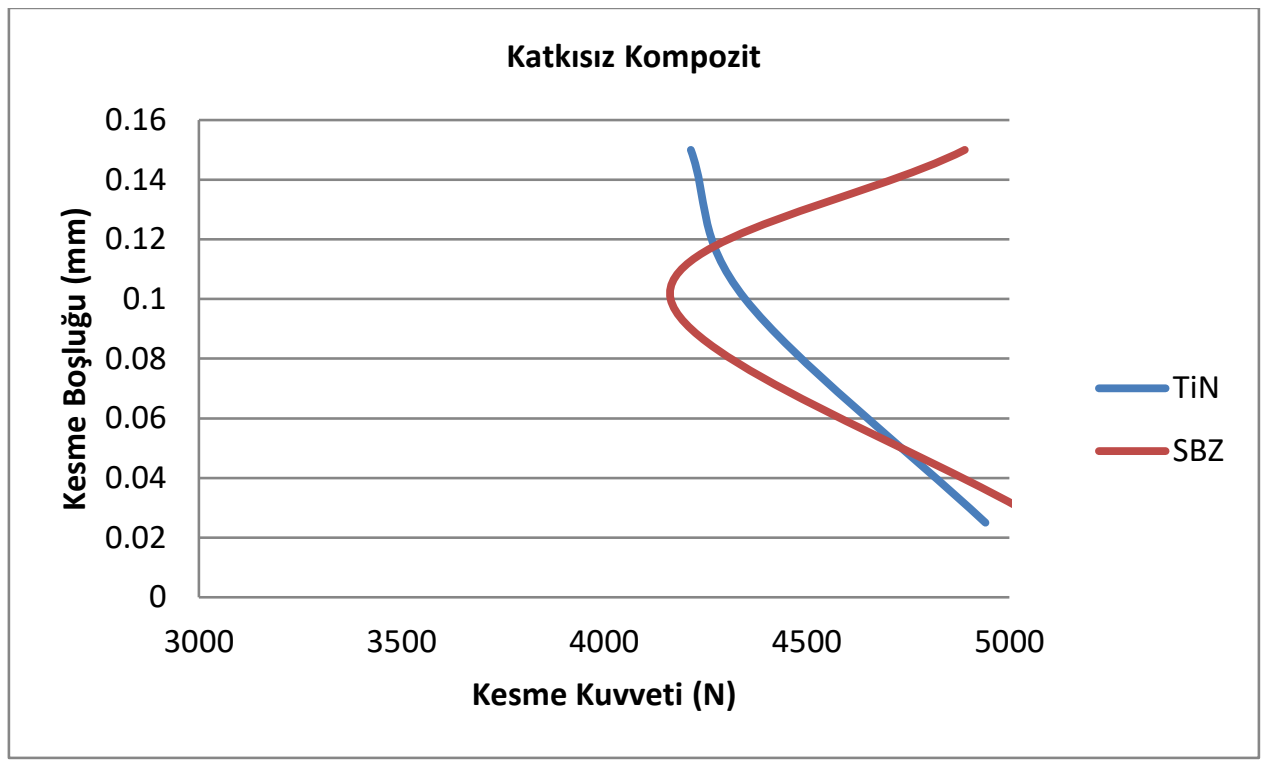

Şekil 4. CETP kompozit kesimde kesme kuvveti değişimi

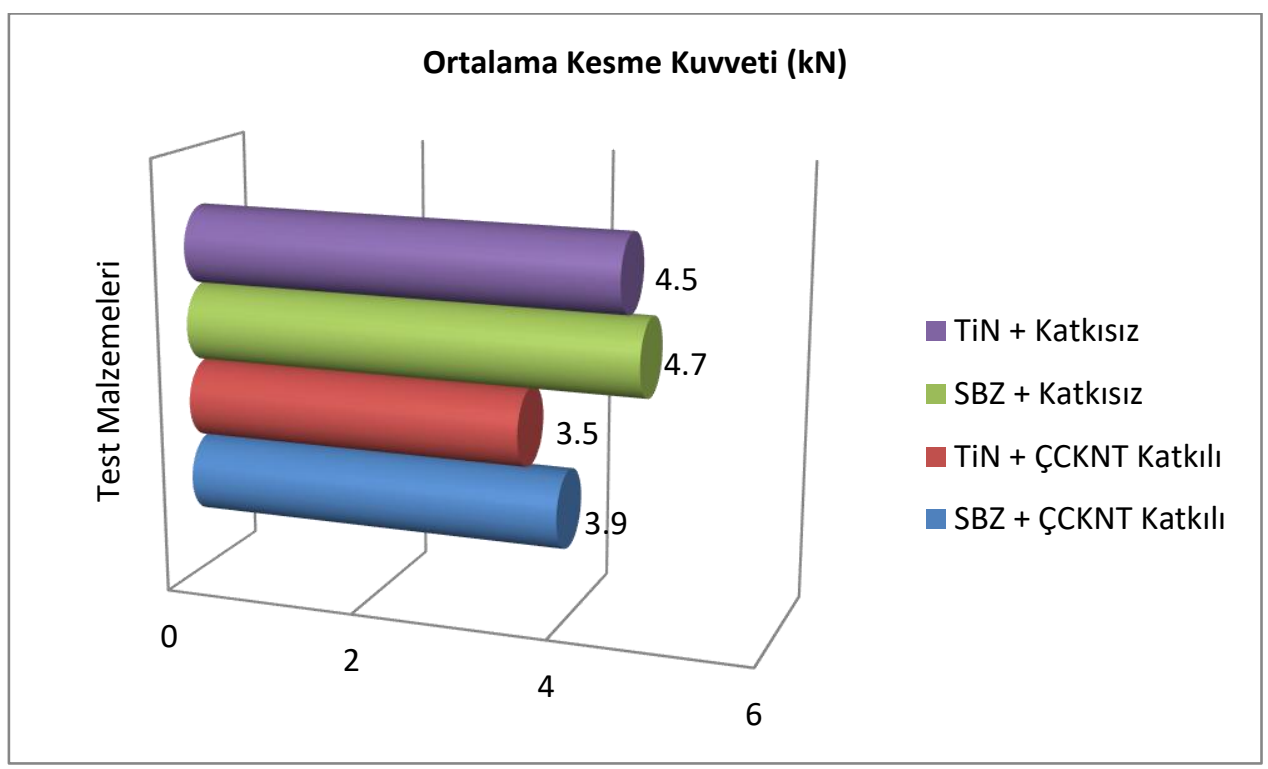

Şekil 5. Test malzemelerine göre ortalama kesme kuvveti

Ortalama kesme kuvvetleri incelendiğinde, kesilen malzeme kalınlığ katkılı kompozit malzemenin SBZ zımba ile kesilmesi sonucu ortalama kesme kuvveti $3.9 \mathrm{kN}$ olarak, aynı tür ve aynı kalınlıkta olan parçaları kesmek için kullanılan zımbalarda kaplama olması durumunda ortalama kesme kuvvetin $3.5 \mathrm{kN}$ değerine düştüğü ölçülmüştür (Şekil.5). 
Benzer durum CETP kompozitlerin Tin kaplı zımbalarla kesilmesinde ihiyaç duyulan ortalama kesme kuvvetinin kaplamasız SBZ zımbalarına göre $4.7 \mathrm{kN}$ değerinden $4.5 \mathrm{kN}$ değerine düşmesi şeklinde tespit edilmiştir.
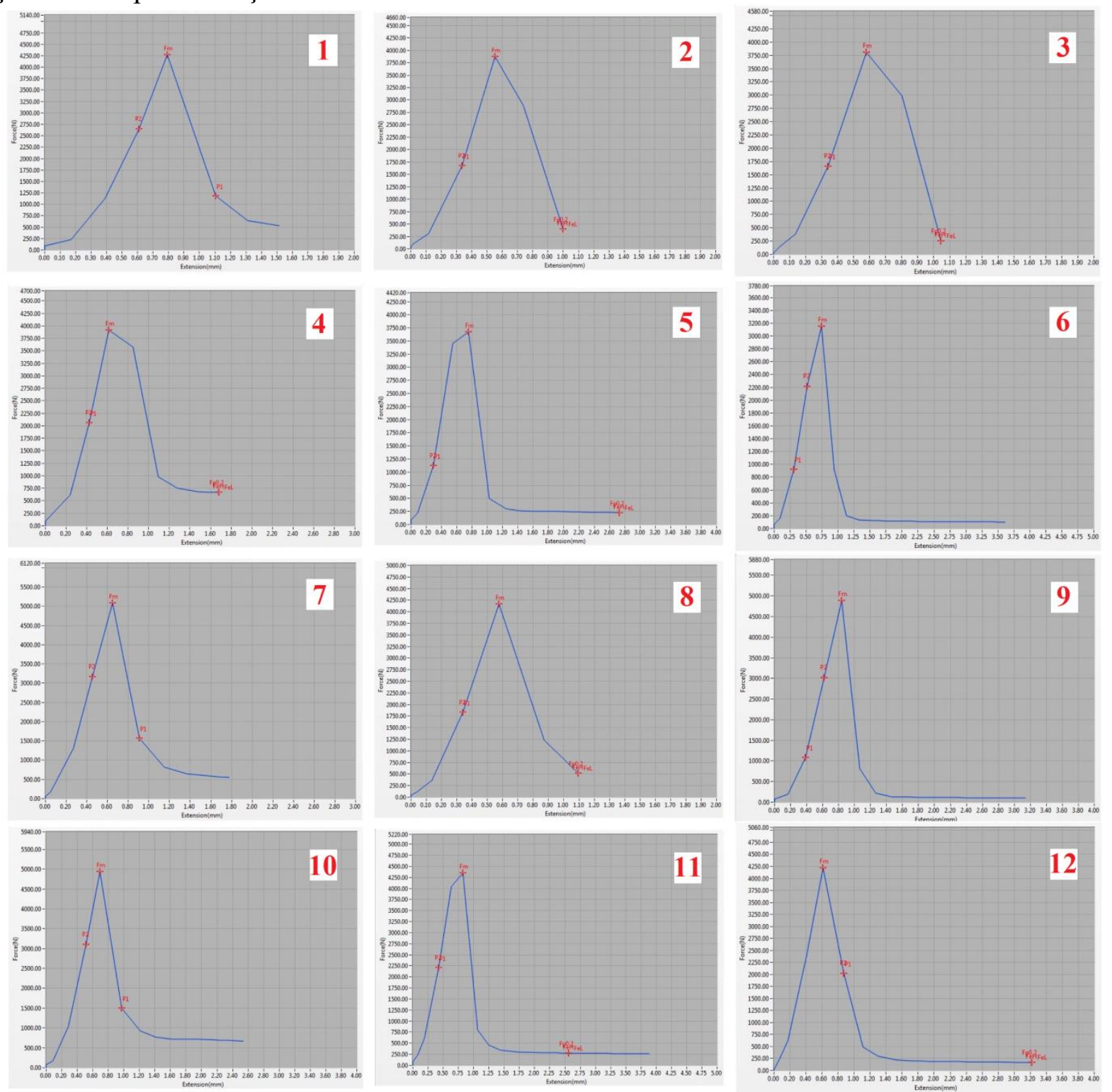

Şekil 6. Kesme kuvveti değişim grafikleri

Şekil 6'da bulunan grafikler incelendiğinde, zımbanın kesilecek olan malzemeye ilk teması sonrası zımba malzemeye batarak kuvvet artışı başlamış daha sonra kesme sonunda kuvvet ihtiyacı azalarak düşmüştür. Kesme kuvvetinin tahmin edilmesinde denklem 1'de belirtilen parametreler dikkate alınmaktadır [15].

$\mathrm{F}=(\mathrm{S}) \mathrm{x}(\mathrm{t}) \mathrm{x}(\mathrm{L})$

Burada F toplam kesme kuvveti, $\mathrm{S}$ şerit malzemenin kesme direnci, $\mathrm{t}$ şerit malzeme kalınlığı, $\mathrm{L}$ 
ise kesilen çevrenin toplam uzunluğudur [15]. Fakat zımba tutucu (klavuz plaka) ve zımba arasındaki sürtünme durumu, zımba kesme yüzeyinin durumu, zımbanın taşlanmış, kaplamalı, polisajlı olması da kesme kuvvetine etki etmektedir. Küçüktürk, farklı kalınlıklardaki AA5754 Alüminyum saclarını farklı kesme boşluğuna sahip kalıplarda delerek; kesme boşluğunun azalmasıyla kesme kuvvetinin arttığını, kesme boşluğunun artması neticesinde zımba batma yüksekliğinin arttığını ve kesme düzlüğü boyunun azaldığını bildirmiştir. Ayrıca kesme boşluğunun artmasının çapak yüksekliğinin artmasına sebep olduğunu bu sebeple kesme kalitesinin düştüğünü rapor etmiştir [16]. Taşdemir, kesme boşluğunun artmasıyla kesme bölgesindeki gerilme dağılımının ve kesme bölgesinin azaldığını, kırılma bölgesinin arttığını bildirmiştir [17]. Zeng ve arkadaşları; CrTiN(krom titanyum nitrür), TiN/NbN, çok katmanlı kaplanmış karbon kompozit gibi kaplamaların zımbaların aşınma direncini iyileştirdiğini kaplamasız zımbaların aşınma durumunda sıyırma kuvvetinin artacağını bildirmişsir [18]. Yüksek sertliğe ve düşük sürtünme katsayısına sahip olan TiN en eski ve en bilinen kaplama çeşididir. Metalin metale sürtünmesinden dolayı oluşan aşınmaları önler, kayganlığı arttırır, yapışma-sarma gibi problemleri minimuma indirger. Günay ve arkadaşları da Tin kaplamanın düşük sürtünme katsayısına sahip olduğu vurgulamışlardır [19]. Bu çalışmada elde edilen sonuçlara göre de delik delmek için kullanılan zımbaların Tin kaplama yapılması kesme kuvvetinin azalmasında rol oynamıştır. Ayrıca seri üretimde kullanılan zımbaların kaplamasız olması durumunda aşınmalarının artabileceği bu durumda zımba körelmelerinden kaynaklı sürtünme ve doğal olarak kesme kuvvetinin artabileceği düşünülebilir.

\section{Sonuçlar ve öneriler}

$\checkmark$ Katkılı ve katkısız kompozitlerin TiN kaplamalı zımba kullanılarak delinmesinde ortalama kesme kuvveti SBZ zımba kullanılarak delinmesine göre sırasıyla \% 10.10 ve \% 4.5 azalmıștır.

$\checkmark$ Yapılan tüm delme işlemlerinde kesme boşluğunun azalmasıyla kesme kuvveti artmıştır.

$\checkmark$ Katkısız kompozitlerin parça kalınlığının katkılı kompozit parça kalınlığına göre daha fazla olması sebebi ile üzerlerine delik delmek için gerek duyulan ortalama kesme kuvvetinin katkılı kompozitlerin delinmesi için gerek duyulan ortalama kesme kuvvetine göre daha fazla olduğu görülmüştür.

Kalıp ve zımba kullanılarak delik elde etme sürecinde ihtiyaç duyulan kesme kuvvetine zımba kaplama malzemesinin etkisini daha detaylı şekilde analiz edebilmek için seri üretimler yapılabilir. Farklı yapılarda, kalınlığı yüksek homojen malzemeler delinerek kesme kuvveti değişimi incelenebilir. Bu şekilde kaplamalı ve polisajlı zımbaların sürtünme ve ısıya karşı dirençleri, kesme kuvvetine etkileri daha detaylı tespit edilebilir. 


\section{Referanslar}

[1] Pickering, K. L., Efendy, M. A., \& Le, T. M. A review of recent developments in natural fibre composites and their mechanical performance. Composites Part A: Applied Science and Manufacturing 2016; 83, 98-112.

[2] Shi, H., Liu, W., \& Fang, H. Damage characteristics analysis of GFRP-Balsa sandwich beams under Four-point fatigue bending. Composites Part A: Applied Science and Manufacturing 2018; 109, 564-577.

[3] Kumar, S., Falzon, B. G., Kun, J., Wilson, E., Graninger, G., \& Hawkins, S. C. High performance multiscale glass fibre epoxy composites integrated with cellulose nanocrystals for advanced structural applications. Composites Part A: Applied Science and Manufacturing 2020; 131, 105801.

[4] Madenci, E., Özkılıç, Y. O., \& Gemi, L. Buckling and free vibration analyses of pultruded GFRP laminated composites: Experimental, numerical and analytical investigations. Composite Structures 2020; 254, 112806.

[5] Gumus, F. B., Ceritbinmez, F., \& Yapici, A. The effect of hexagonal nano boron nitride on mechanical performances and machinability behaviors of basalt fabric reinforced epoxy composites. Proceedings of the Institution of Mechanical Engineers, Part C: Journal of Mechanical Engineering Science 2021; 09544062211013374.

[6] Das, S., Halder, S., Khan, N. I., Paul, B., \& Goyat, M. S. Assessing damage mitigation by silanized milled graphite nanoparticles in hybrid GFRP laminated composites. Composites Part A: Applied Science and Manufacturing 2020; 132, 105784.

[7] Ceritbinmez, F., Yapici, A., \& Kanca, E. The effect of nanoparticle additive on surface milling in glass fiber reinforced composite structures. Polymers and Polymer Composites 2021; 09673911211014172.

[8] Gemi, L., Morkavuk, S., Köklü, U., \& Gemi, D. S. An experimental study on the effects of various drill types on drilling performance of GFRP composite pipes and damage formation. Composites Part B: Engineering 2019; 172, 186-194.

[9] Ceritbinmez, F., \& Yapıc1, A. Kompozit Malzemelerin Delinmesinde Matkap Nokta Açısının ve ÇCKNT'lerin Etkisi. Academic Perspective Procedia 2020; 3(1), 180-188.

[10] Ceritbinmez, F., Özkan, V., Saracoglu, G., \& Yapici, A. MWCNTs doped GFRPs drilling: crosscheck among holes obtained by alternative manufacturing methods. The International Journal of Advanced Manufacturing Technology 2021; 1-9.

[11] Qiao, J. W., Ye, H. Y., Yang, H. J., Liang, W., Xu, B. S., Liaw, P. K., \& Chen, M. W. Dynamic shear punching of metallic glass matrix composites. Intermetallics 2013; 36, 3135.

[12] Chan, H. Y., Abdullah, A. B., Samad, Z., \& Zain, M. S. M. Precision punching on laminates composite panel: effect of dual-stages puncher. International Journal of Materials Engineering Innovation 2015; 6(4), 288.

[13] Zain, M. S. M., Abdullah, A. B., \& Samad, Z. Effect of puncher profile on the precision of punched holes on composite panels. The International Journal of Advanced Manufacturing Technology 2017; 89(9-12), 3331-3336.

[14] Abdullah, A. B., Zain, M. S. M., \& Samad, Z. Delamination assessment of punched holes on laminated composite panels based on the profile measurement technique. The 
International Journal of Advanced Manufacturing Technology 2017; 93(1), 993-1000.

[15] Groover, M. P. Fundamentals of modern manufacturing: materials, processes, and systems. 4rd ed. John Wiley \& Sons; 2010.

[16] Küçüktürk, G. AA5754 Malzemenin kesme işlemlerinde kesme boşluğunun ürün kalitesine etkilerinin deneysel incelenmesi ve bulanık mantık ile tahmini. Gazi Üniversitesi Mühendislik Mimarlık Fakültesi Dergisi 2016; 31(2).

[17] Taşdemir, V. Hassas kesme işlemine malzeme kalınlığı ve kalıp boşluğunun etkisinin sonlu elemanlar yöntemi ile analizi. Uluslararası Mühendislik Araştırma ve Geliştirme Dergisi 2018; 10(2), 127-134.

[18] Zeng, X. T., Zhang, S., \& Muramatsu, T. Comparison of three advanced hard coatings for stamping applications. Surface and Coatings Technology 2000; 127(1), 38-42.

[19] Günay, H., Engin, Y., Güven, E. A., \& Sınmazçelik, T. 1.2379 Soğuk İş Takım Çeliği Delme Zımbalarında AlTiN, TiSiN ve TiN, PVD Kaplamaların Takım Ömrüne Etkisi. Kocaeli Üniversitesi Fen Bilimleri Dergisi 2020; 3(2), 154-159. 